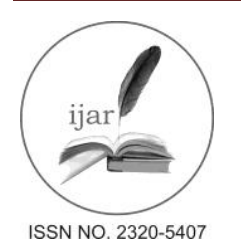

Journal homepage: http://www.journalijar.com

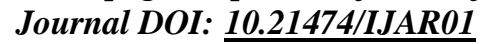

INTERNATIONAL JOURNAL

OF ADVANCED RESEARCH

RESEARCH ARTICLE

\title{
IDIOPATHIC DILACERATION IN DECIDUOUS DENTITION: A CASE SERIES WITH REVIEW OF
} LITERATURE.

\author{
Harveen S. Kalra ${ }^{1}$, Ramesh Kumar Pandey ${ }^{2}$, Heena ${ }^{1}$, Afroz Alam Ansari ${ }^{3}$. \\ 1. M.D.S., Lecturer, Department of Periodontics, Genesis Institute of Dental Sciences \& Research, Ferozepur. \\ 2. M.D.S., Professor \& Head, Department of Pedodontics, Faculty of Dental Sciences, K.G.M.C., Lucknow \\ 3. M.D.S., Associate Professor, Department of Pedodontics, Faculty of Dental Sciences, K.G.M.C., Lucknow
}

\section{Manuscript Info}

Manuscript History:

Received: 14 February 2016

Final Accepted: 19 March 2016

Published Online: April 2016

Key words:

Apical root dilaceration, idiopathic

developmental disturbance,

deciduous dentition.

*Corresponding Author

Harveen S. Kalra.

\begin{abstract}
The prevalence of traumatic injuries to the primary dentition ranges from $11 \%-30 \%$, but the incidence of dilacerated permanent teeth is very low and disproportionate to high prevalence of trauma. Hence, traumatic injuries to the primary dentition are unlikely to account for all cases of dilaceration and especially those of primary teeth themselves. An idiopathic developmental disturbance to deciduous dentition is proposed as another possible cause in cases that have no clear evidence of traumatic injury. The prime objective of the present article is to discuss cases of dilaceration in the deciduous anterior teeth and review the previous studies on dilacerations of the deciduous dentition.
\end{abstract}

Copy Right, IJAR, 2016,. All rights reserved.

\section{Introduction:-}

Dilaceration is defined as a distortion occurring during development of a tooth which disrupts the normal axial relationship between crown and $\operatorname{root}^{1}$ and can occur anywhere along the length of the tooth i.e., its crown, cementoenamel junction, along the root, or only involving the apex of the root. The term was first used by Tomes and referred to as 'forcible separation of the cap of the developed dentine from the pulp in which the development of dentine is still progressing, ${ }^{2}$. Most authorities confirm the two possible causes of dilaceration. The most widely accepted cause is mechanical trauma to the primary predecessor tooth, which results in dilaceration of the developing succedaneous permanent tooth. The cases of root dilacerations and other forms of injury to deciduous dentition are reported in infants with prolonged endotracheal intubation or any kind of trauma during infancy ${ }^{3-6}$. An idiopathic developmental disturbance is proposed as another possible cause in cases that have no clear evidence of traumatic injury. However, there is paucity of literature and very few cases have been reported till now ${ }^{7-13}$. The present article illustrate six cases of idiopathic deciduous apical root dilaceration (ARD) and reviews emphasizing dilaceration of the deciduous teeth.

\section{Case 1:-}

A seven year old female patient came with pain in the left upper anterior region. The parent reported presence of hard tissue protruding through the labial mucosa above left primary central incisor since two weeks. The parent narrated history of trauma to the tooth one year back. Clinical evaluation depicted carious lesions mesially of primary maxillary right and left central incisor. Primary maxillary left central incisor (PMLCI) was tender, slightly extruded and showed grade I mobility (fig.1a). Intra oral periapical X-ray (IOPA) showed root abnormality in the apical third and hard tissue in the labial sulcus was suspected as root apex (fig.1b). PMLCI was planned for routine extraction under local anaesthesia. Some difficulty was experienced during extraction procedure as the tooth offered greater resistance to pulling force than normal. On extraction, it was evident that the root of the tooth was 
dilacerated in apical third (fig.1c). Patient was advised antibiotic therapy and recall visit being scheduled after one month. The patient didn't turn up and reported after 3 months with a draining sinus in the periapical region of primary maxillary right central incisor (PMRCI; fig.1d). Radiograph revealed some root abnormality in PMRCI and was planned for extraction (fig. 1e). After extraction, PMDCI also revealed similar dilaceration (fig. 1c). Dentascan was advised to observe dilacerations in teeth which depicted similar root morphology as PMRCI and PMLCI (fig. 2a $\&$ b). Since, mandibular deciduous incisors were undergoing resorption, so it is not justified to comment on their morphology. Dentascan revealed curvatures in other teeth also. Patient further reported after 3 months for recall check-up with partially erupted permanent maxillary left central incisor (fig. 1f).

\section{Case 2:-}

An eight year old female patient's parent reported the presence of double teeth in the upper right anterior region. Clinical examination revealed palatally erupting permanent maxillary right central incisor with apical fenestration (AF) of PMRCI (fig.3a). PMRCI was planned for extraction and pre-operative IOPA was obtained (fig. 3b). Extraction revealed dilaceration of root in the apical third without the history of trauma to that region (fig 3c).

\section{Case 3:-}

The case was presented to the post graduate unit when a trainee broke the apical $1 / 3^{\text {rd }}$ of primary maxillary right canine during extraction in a 15 year old female patient. The remaining apical portion was extracted with the help of apexo elevator as there was no permanent tooth present at the apex of this fractured root on the radiograph (fig 3d). An attempt was made to approximate the two pieces extraorally and it was observed that the root was dilacerated in the apical third (figure 3 e \& f).

\section{Case 4:-}

A seven year old male patient reported with pain in the right upper anterior from the last two days. The clinical examination revealed AF and abscess in relation to gingival region of PMRCI (fig 4a). The extraction was planned for all the four root stumps in that region and pre-operative IOPA was recorded (fig.4b). Extractions depicted APD in all the four primary maxillary incisors (fig. 4c\&d).

\section{Case 5:-}

The patient reported with pain in the upper right anterior region since last 1 week. The clinical examination depicted AP of PMRCI with ectopically erupting permanent maxillary right central inscisor (fig.5a). Pre-operative IOPA was done and extraction was planned for both PMRCI and PMLCI (fig.5b). Extractions depicted ARD in PMRCI and PMLCI (fig.5c).

\section{Case 6:-}

An 8 year old patient's parent reported a protruding hard tissue from the upper right region of the oral cavity from the last 1 month. The parent narrated history of trauma to that area 2 months back. Clincally it was found to be root apex of PMRCI (fig.5d) and IOPA was recorded (fig. 5e). Extraction depicted ARD of PMRCI. Histological analysis of all the extracted teeth showed normal tubular pattern and tooth structure and not that are characteristic of those seen after traumatic injuries (fig. $6 \mathrm{a} \& b$ ).

\section{Review of literature:-}

Several authors studied the various cases of dilaceration in the deciduous teeth which is summarized in table 1. Gorlin and Goldman $(1970)^{11}$ presented a case of dilacerated primary tooth in utero of a 6 month old foetus in which a distinct bend was seen in the Hertwig's root shealth of the developing primary tooth germ. Primary dilacerated tooth was an incidental finding by Kelly et al $(1976)^{10}$ in which there was AF and the tooth had a concave labial curvature. Bimstein $(1978)^{7}$ described a case in which two mandibular primary incisors failed to erupt and surgical exploration revealed that the crowns and coronal portion of their roots were lying horizontally across the line of the arch whilst the most apical part of the roots deviated vertically into the alveolar bone. Kinirons $(1983)^{8}$ reported two similar cases of a maxillary primary incisor and a mandibular permanent first molar that had failed to erupt and were subsequently found to be dilacerated. As the distorted teeth had no predecessors and were unerupted, dilacerations were assumed to be developmental in origin. Angelos et al (1989) ${ }^{6}$ critically reviewed the oral complications associated with neonatal oral tracheal intubation and stated primary tooth dilaceration as its complication. Seow et al $(1990)^{3}$ reported a case of dilaceration in maxillary left primary incisor of a 20 month old child who was born premature and on ventilator for the first 14 days of his birth. Kilpatrik et al $(1991)^{9}$ presented a case in which a nonvital maxillary primary incisor failed to resorb, exhibiting root apex in the labial sulcus and was found to be 
dilacerated on extraction. Yeung et al (2003) $)^{12}$ quoted a case of compound odontome associated with an unerupted and dilacerated maxillary primary left central incisor in a young patient and highlighted the possible causal relationship between odontome and dilaceration. Jung et al $(2012)^{13}$ conducted a three dimensional analysis of deciduous maxillary anterior teeth using cone-beam computed tomography in 38 young healthy children. They confirmed buccal root dilaceration of $26.3^{\circ}$ in primary maxillary central incisors (PMCI), $16.5^{\circ}$ in primary maxillary lateral incisors (PMLI) and $17.5^{\circ}$ for primary maxillary canines (PMC). Dilacerations occurred in $48.9 \%$ of the root length for PMC, 54.8\% for PMCI, and 57.3\% for PMLI.

Table 1: Prevalence of dilacerations in deciduous teeth: Summary of reports in dental literature.

\begin{tabular}{|l|l|l|l|l|l|}
\hline Author(s) & Year & Tooth Type & Race & $\begin{array}{l}\text { No. of } \\
\text { Dilacerations }\end{array}$ & Etiology \\
\hline Gorlin and Goldman & 1970 & N/A & N/A & 1 & Developmental \\
\hline Kelly et al. & 1976 & N/A & N/A & N/A & Developmental \\
\hline Bimstein & 1978 & Md. CI's & N/A & 2 & Developmental \\
\hline Kinirons & 1983 & Mx. CI's & N/A & 2 & Developmental \\
\hline Angelos et al. & 1989 & N/A & N/A & N/A & Traumatic \\
\hline Seow et al. & 1990 & Left Mx. CI & N/A & 1 & Traumatic \\
\hline Kilpatrick et al. & 1991 & Right Mx.CI & Caucasian & 1 & Developmental \\
\hline Yeung et al. & 2003 & Right Mx. CI & Chinese & 1 & Developmental \\
\hline Jung et al. & 2012 & Ant. Mx. teeth & Korean & 80 & Developmental \\
\hline
\end{tabular}

\section{Discussion:-}

Dilaceration is being observed in both permanent and deciduous dentitions, while the incidence in the deciduous dentition is reported to be low ${ }^{4}$. Primary incisors erupt between 6 and 9 months after birth and their root development takes another 12 to 18 months. To affect apical part of the roots of primary teeth, as in all the above cases, the trauma must have occurred a few months after its eruption but the history of trauma's were not found to be that early. The shape of the dilacerated teeth in the cases described above facilitate AF as the erupting permanent successor can easily push the unresorbed root apex through thin labial bone. Jung et $\mathrm{al}^{13}$ stated that deciduous root labio/buccal dilaceration in anterior region are normal phenomenon and root dilacerations of deciduous teeth are rarely detected due to difficulty in obtaining sound deciduous teeth for measurement because of physiological root resorption prior to permanent teeth eruption. Periapical radiographs, recorded using paralleling technique, are considered the clinical gold standard for measuring crown and root length but these conventional radiographic methods for evaluating tooth anatomy are not reliable because they convert a three dimensional structure into two dimensional view with distorted shape and size. So, there is paucity of literature indicating ARD of primary maxillary anterior teeth.

\section{Clinical implication:-}

The anatomy of deciduous teeth is especially important for restorative or endodontic treatments performed by pediatric dentists. In an attempt to endaevour endodontic procedures, the clinician must exercise great care to avoid root perforation of teeth with significant dilacerations. Treatment that does not account for the tooth root curvature leads to excessive removal of the root internal wall. The buccal curvature of the dental root (ARD) and its degree of curvature can be important factors in cases of trauma-induced intrusion or lateral luxation of the deciduous incisors. The cases of lateral luxation with buccally displaced roots have a relatively lower risk of permanent tooth damage. However, in cases with palatally displaced roots showed a relatively higher risk of permanent tooth damage.

The present article adds to literature about the new morphological root evidence contrary to earlier studies. ARD is common phenomenon to provide more room for the erupting permanent incisors as evidenced by Jung et al (2012) ${ }^{13}$

\section{Proposed hypothesis:-}

Primary maxillary central incisors begin to calcify at about 14 weeks in utero, crown completion occurs at about $1 \frac{1 / 2}{2}$ months and root completion at $1 \frac{1}{2}$ years. Permanent maxillary incisors begin to calcify at about 3-4 months and buds are palatal and apical to the primary incisors. The unequal pressure from the growing buds might be responsible for ARD in primary incisors. 


\section{Figure legends:-}

\section{Figure 1:-}

Case 1(a) - Apical fenestration in primary maxillary left central incisor.

(b) - Radiograph showing bull's eye phenomenon on the apical third of primary maxillary left central incisor.

(c) - Post-extraction of primary maxillary left \& right central incisor.

(d) - Sinus formation over the apical region of primary maxillary right central incisor and eruption bulge of permanent maxillary left central incisor.

(e) - Radiograph showing cervical migration of permanent maxillary left central incisor.

(f) - Partially erupting permanent maxillary left central incisor.
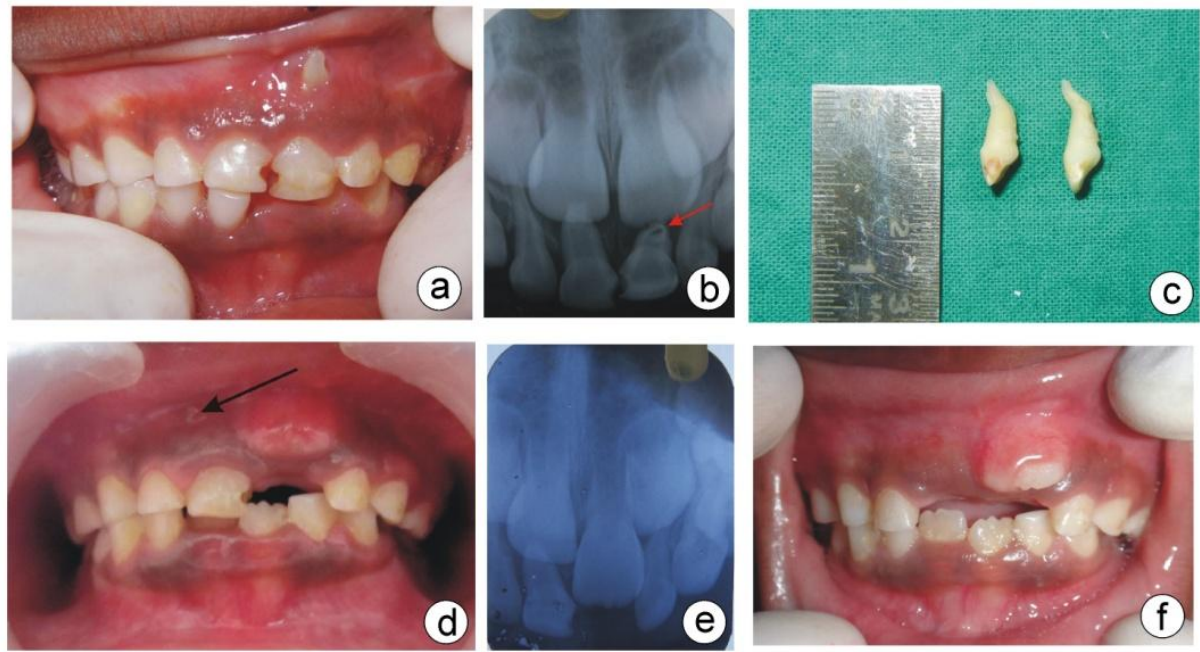

\section{Figure 2:-}

Case 1 - Dentascan indicating curvatures (arrows) in

(a) - Primary maxillary right lateral incisor and primary mandibular right canine

(b) - Primary maxillary left lateral incisor and primary mandibular left canine.
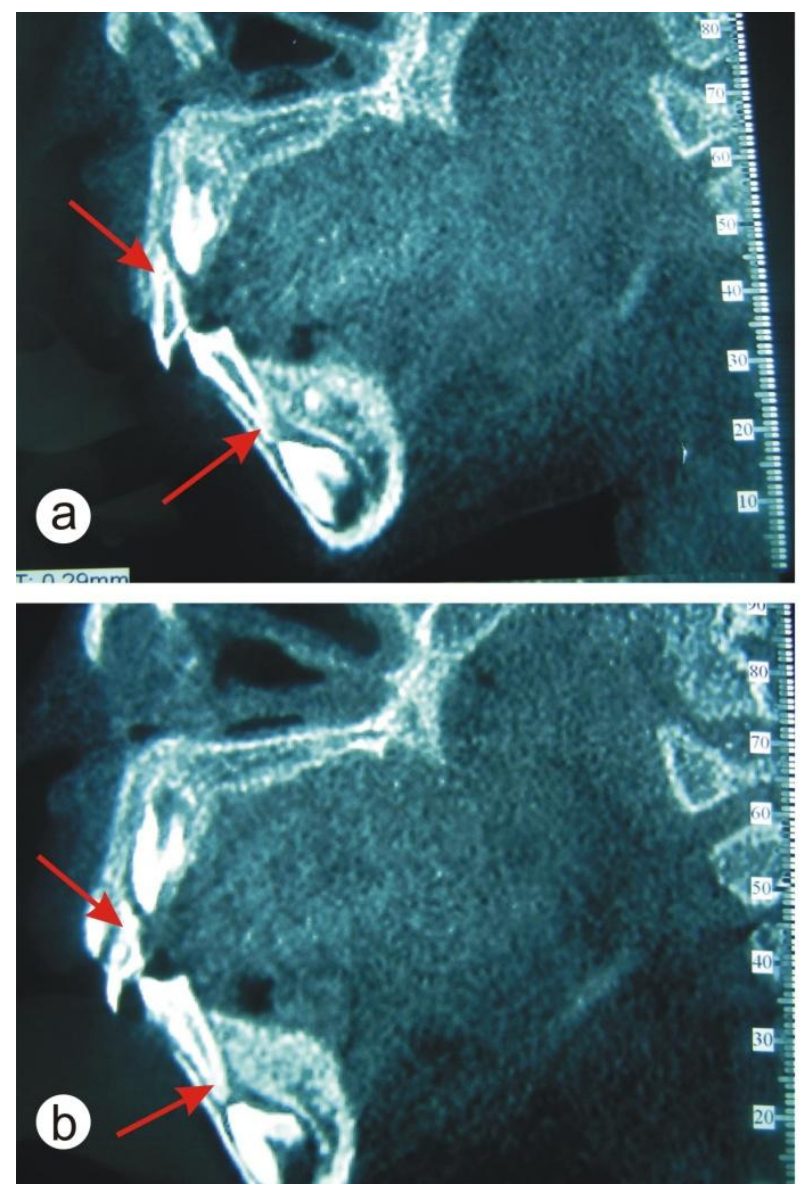


\section{Figure 3:-}

Case 2(a) - Preoperative photograph depicting apical fenestration in primary maxillary right central incisor.

(b) - Intra oral periapical radiograph of primary maxillary right central incisor.

(c) - Post - extraction photograph of primary maxillary right central incisor.

(d) - Intra oral periapical radiograph of primary maxillary right canine (arrow)

(e\&f) - Extracted tooth with the two separated pieces and with the pieces approximated respectively.
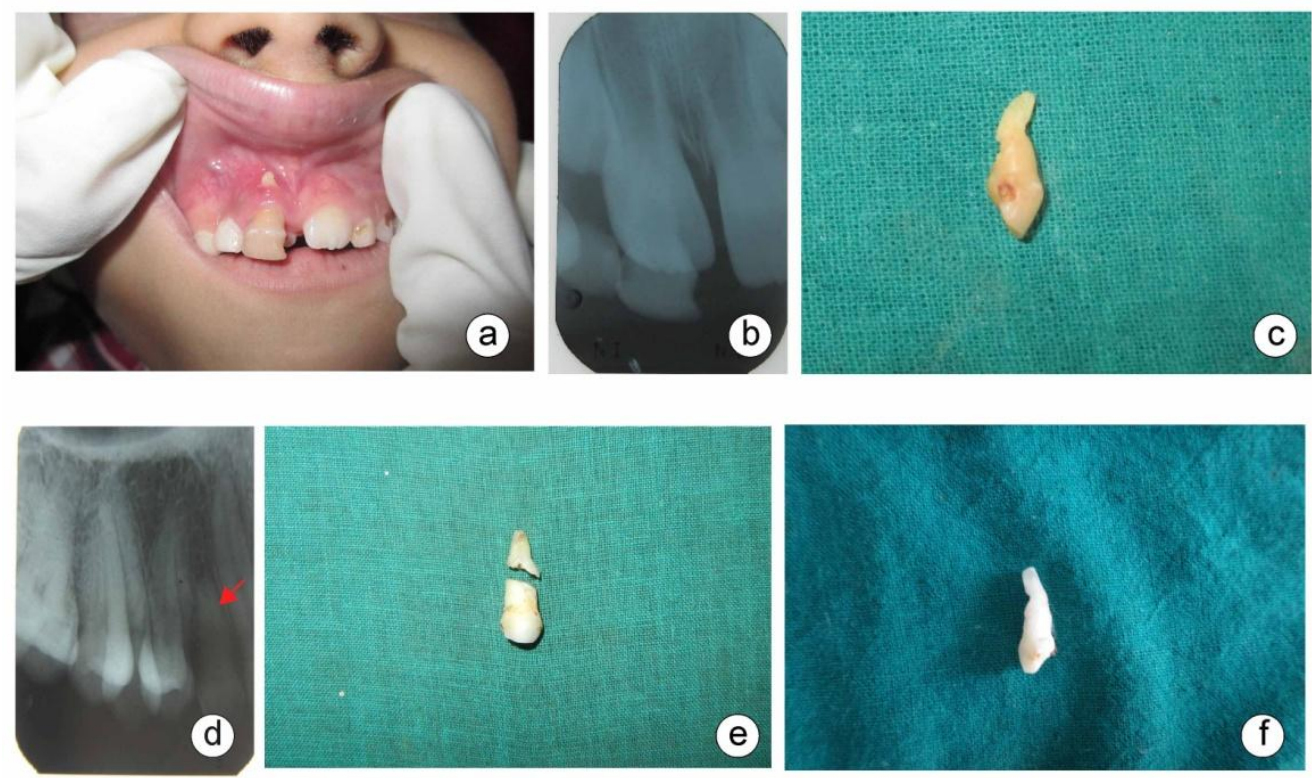

\section{Figure 4:-}

Case 4 (a) - Preoperative photograph depicting apical fenestration in primary maxillary right central incisor. (b) - Intra oral periapical radiograph of primary maxillary anterior region.

(c\&d) - Post-extraction photograph of primary maxillary anterior region, frontal and lateral view respectively.
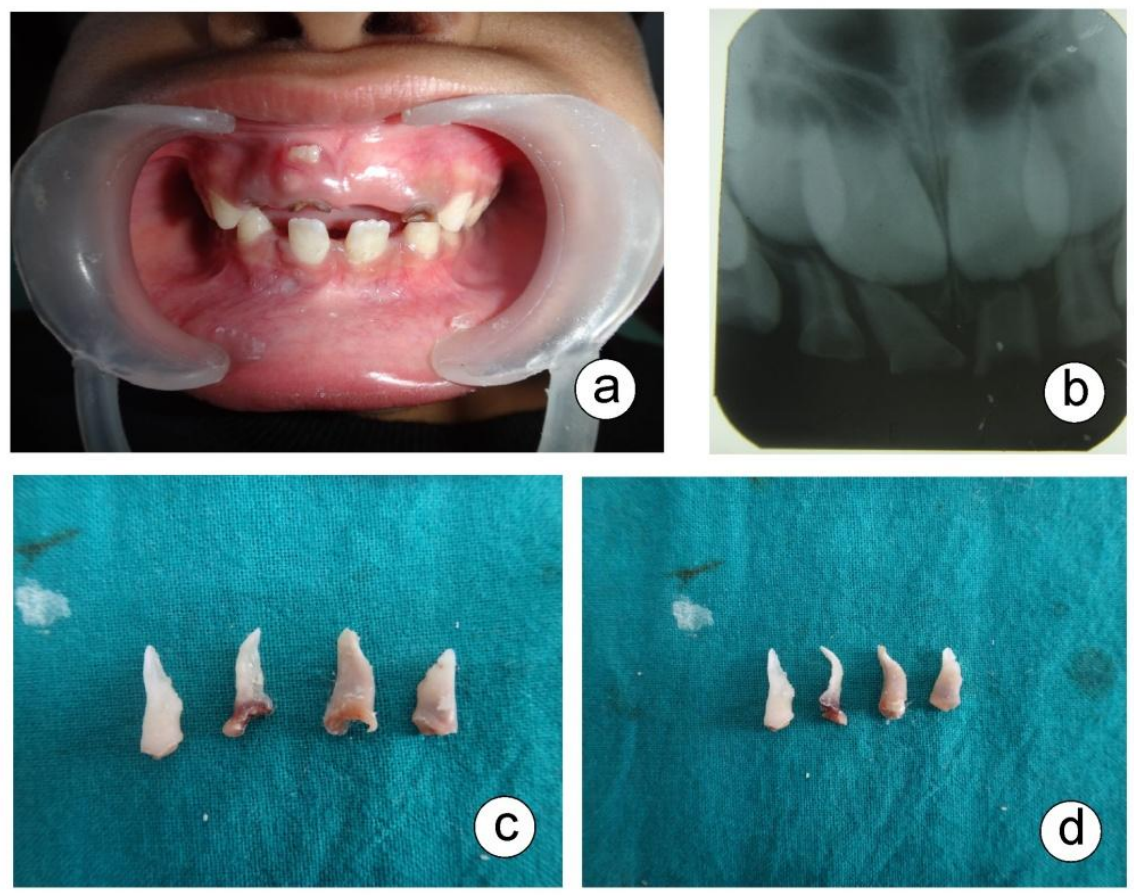


\section{Figure 5:-}

Case 5(a) - Preoperative photograph depicting apical fenestration in primary maxillary right central incisor. (b) - Intra oral periapical radiograph of primary maxillary right central incisor.

(c) - Post-extraction photograph of primary maxillary right and left central incisor.

Case 6(d) - Preoperative photograph depicting apical fenestration in primary maxillary right central incisor. (e) - Intra oral periapical radiograph of primary maxillary right central incisor.
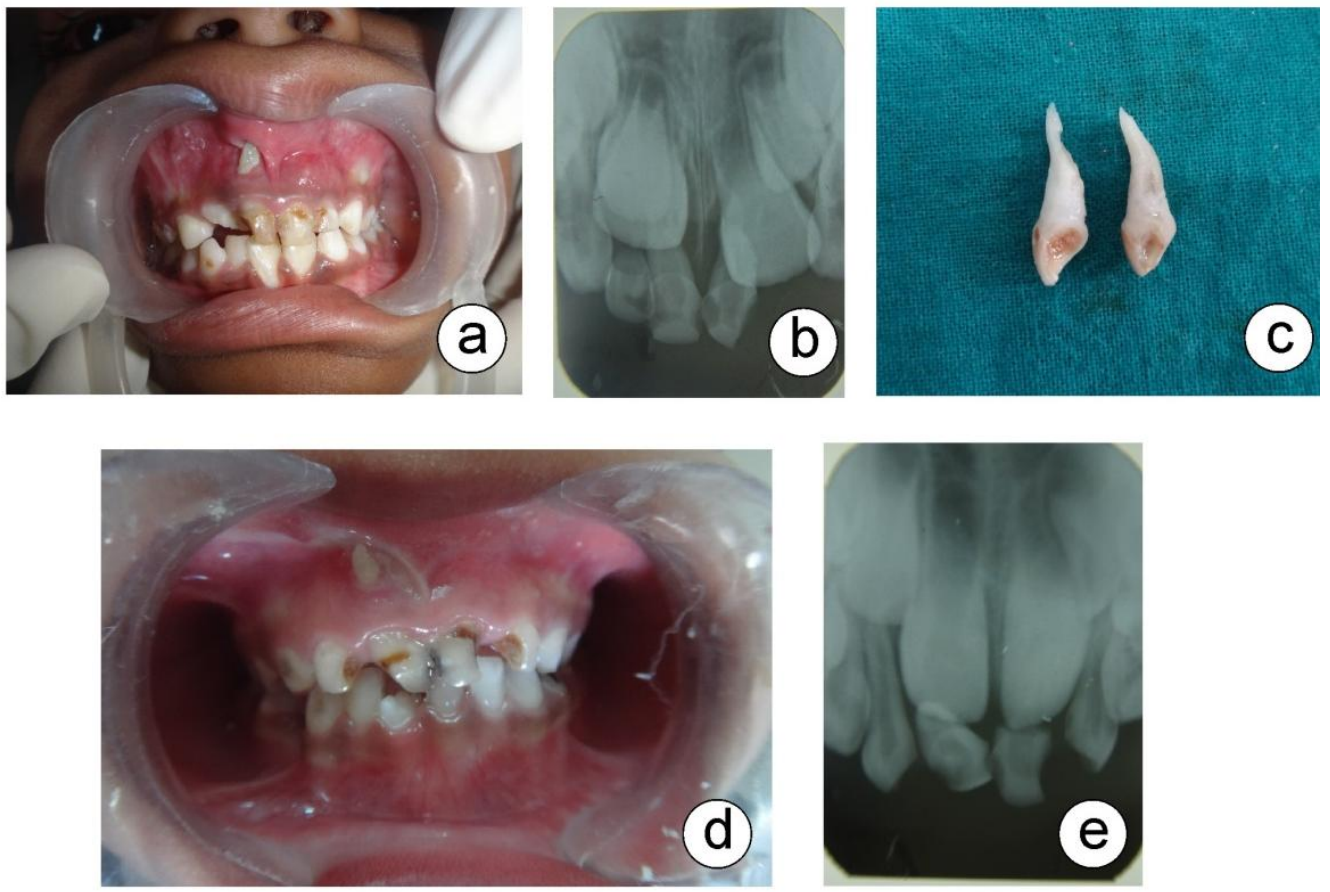

Figure 6:-

(a) \& (b) - Ground sections of extracted teeth under $10 \mathrm{x}$ magnification.

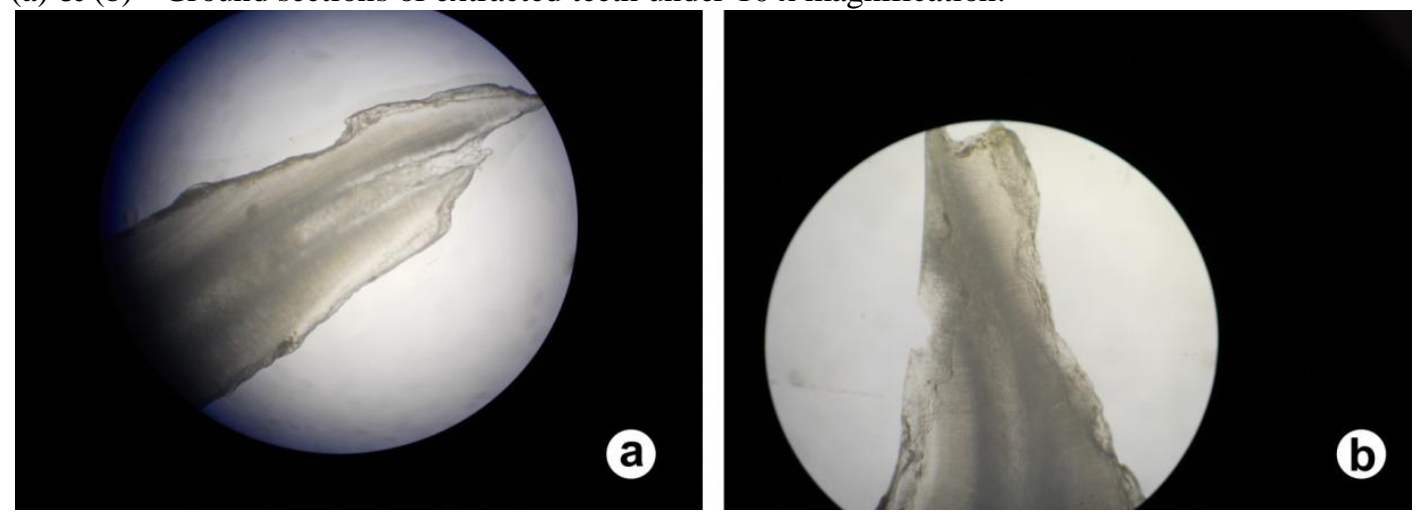




\section{References:-}

1. Harty FJ, Ogston RO. (1987): Concise Illustrated Dental Dictionary. Bristol: Wright; 67.

2. Tomes J. (1848): A course of lecture on Dental physiology and Surgery: London; Quoted by Mathis.

3. Seow WK, Perham S, Young WG. (1990): Dilaceration of a primary maxillary incisor associated with neonatal laryngoscopy. Pedi-atr Dent; 12: 321-4.

4. Neville BW, Damm DD, Allen CM, Bouquot JE. (2002): Oral and maxillofacial pathology. Philadelphia: WB Saunders Co;p. 86-8.

5. Proffit WR, Fields HW Jr, Ackerman JL, Bailey LJ, Camilla Tulloch JF. (2000): Contemporary orthodontics. St Louis: Mosby; p. 78, 124, 315, 632, 723.

6. Angelos GM, Smith DR, Jorgenson R, Sweeney EA. (1989): Oral complications associated with neonatal oral tracheal intubation: a critical review. Pediatr Dent; 11: 133-40.

7. Bimstein E. (1978): Root dilacerations and stunting in two unerupted primary incisors. Journal of Dentistry for Children; 45: 223-5.

8. Kinirons MJ. (1983): Dilaceration and failure to erupt of non- successional teeth. Journal of the Irish Dental Association; 29: 53-4.

9. Kilpatrick NM, Hardman PJ and Welbury RR. (1991): Dilaceration of a primary tooth. International Journal of Paediatric Dentistry; 1: 151-3.

10. Kelly JR, Keeton JM, Barr ES. (1976): Apical Fenestration. Journal of Dentistry for Children; 43: 96-8.

11. Gorlin RJ, Goldman HM. (1970): Thoma's Oral Pathology, $6^{\text {th }}$ St Louis: C V Mosby Company; 105 - 6.

12. Yeung KH, Cheung RCT and Tsang MMH. (2003): Compound odontoma associated with an unerupted and dilacerated maxillary primary central incisor in a young patient International Journal of Paediatric Dentistry; 13: $208-12$.

13. Jung, MS, Lee SP, Kim GT, Choi SC, Park JH and Kim JW. (2012): Three-dimensional analysis of deciduous maxillary anterior teeth using cone-beam computed tomography. Clinical Anatomy; 25: 182-8. 